\title{
A survey on mobile devices use by university students
}

\author{
Carmen Hernández*, Jesús Vegas*, César Llamas*, Manuel Á. González \\ *Departamento de Informática. Universidad de Valladolid \\ \{chernan, jvegas, cllamas\}@infor.uva.es \\ $\dagger$ Departamento de Física Aplicada. Universidad de Valladolid \\ manuelgd@termo.uva.es
}

\begin{abstract}
New mobile devices are changing the habits and preferences of students and instructors. In spite of the ever increasing market and software utilities that appear everyday, relatively little is known about the way the students use these tools in their study tasks. To alleviate this lack, a survey has been conducted with university students trying to portray how they use mobile devices in their studying activities.

As a main result we see that more than half of the students use some mobile devices in their study tasks with different intensity, being the smartphone the preferred device. Some discrepancies have been found when comparing their use in the academic context and in the real life. The influence of the use of mobile devices on the way in which the students work is also studied; the habit of studying in-group and using mobile devices are closely related. Finally, the role of instructors, encouraging or forbidding the use of mobile devices, has also been analyzed. From the results of our survey, we can conclude the professors do not support enough the use of these devices for learning.
\end{abstract}

Keywords-Educational Technology, Computer Aided Instruction, Mobile Learning, Mobile and Personal Devices

\section{INTRODUCTION}

Within the context of ubiquitous computing, the computing systems are part of everyday environment, and user's interaction with them is possible wherever the user needs it. This is getting increasingly true with the use of the smartphones and tablets, which are becoming not only full time connection devices, but powerful computation machines. So, it's not surprising that mobile devices will become part of all our activities as may be teaching and learning. However, the implementation of a learning structure that naturally incorporates the use of mobiles or tablets in the classroom seems to be very far of being true for many teachers, in spite of the large number of works that have analyzed the influence of mobile devices in the classroom. This is the main reason to do a survey in order to find out not only how students use mobile devices (laptops, smartphones, tablets, ebooks,...) in the classroom but also to know how teachers encourage or discourage that use.

In this study, it has been considered the use of mobile devices as the key concept which allows qualifying the learning process as mobile learning, putting less weight on the place where it takes. This is consistent with the more classical definitions of mobile learning as stated by [1].

The structure of the remainder of the paper is as follows: In Section II the survey will be introduced. Section III reports the main results of the research, which will be discussed in the Section IV. Finally, Section V presents some conclusions and discusses limitations and further work.

\section{MATERIALS AND METHODS}

The study described in this paper is part of a larger study [2] designed to get information on the students' studying habits as well as their use of mobile devices in their academic activities.

The main bulk of participants were expected to come from students in our Computer Engineering School as the survey was announced using notice boards, lecture rooms and through social networks accounts used to share information on different subjects of the School. However, in order to increase the number of participants, also some announcements of the survey were made in some mobile and computer users forums. A web based survey method was chosen instead of a direct observation method in order to ease the participation of the students, giving them more freedom to choose when and where they wanted to answer the survey, and to have the possibility of receiving additional participants from different locations, though most of the participants were expected to belong to our own School. The expected profile of the participants, considering how the survey was publicized, allow us to assume that they feel comfortable using mobile technology and its possible problems in the learning environment will not be an issue hindering the acceptance of this technology in a similar way as in [3]. The survey involving a total number of 111 participants. The gender split of the participants was $66 \%$ male, $34 \%$ female.

Topics of the survey were designed to answer the following research items:

1) What is the degree of penetration of mobile devices in the learners' studying activities?

2) What is the main purpose of using mobile devices by the learners?

3) Does it exist any relationship between the use of the mobile devices and the academic results?

4) What is the role played by the teachers in the students' use of mobile devices?

In order to answer those questions and to understand the relationships between mobile use in learning and other students characteristics, the survey included items on: (1) students' general information, (2) students' use of mobile devices, (3) utility of mobile devices as perceived by the students, (4) use 
TABLE I. PERCENTAGE OF STUdENTS ACCUSTOMED TO DO ACCOMPANIMENT ACTIVITIES WHILE STUDYING.

\begin{tabular}{lcc}
\hline Usual accompaniment activities & 'Yes' & 'No' \\
\hline Music & 53.2 & 46.8 \\
Chat on line & 52.3 & 47.7 \\
Radio & 16.2 & 83.8 \\
Television & 10.8 & 89.2 \\
\hline
\end{tabular}

TABLE II. PERCENTAGE OF STUDENTS WHO STUDY IN-GROUP DEPENDING ON THE FREQUENCY OF IT.

\begin{tabular}{ccc}
\hline Usually & Sometimes & Never \\
\hline 9.0 & 40.5 & 50.5 \\
\hline
\end{tabular}

of mobile devices in the classroom, and (5) satisfaction of the students with their academic results.

\section{RESULTS}

Among the whole set of items that the students were asked to answer, in this case the analysis will be focussed only on the items concerning the topics described above. These items along with their results are discussed in the following subsections and in Tables I to VII.

The first set of questions was focused on the context of study. The intention is to look for relationships between the answers in these questions and those related with the use of mobile devices.

With the first question was wanted to know about the environment of study, that is, if the students use to study with music, TV, radio, or connected to an Internet chat service. The results of this question are shown in Table I. According to the results in that table more than a half of the students are connected to the Internet and using a chat room while studying, and the percentage of students listening to music while studying is nearly the same.

The second question was intended to know if the students use to study alone or in-group and what was the proportion of total studying time used in either way. The students were asked to say if they form groups to study choosing one among the following options: 'Never', 'Only in occasions, e.g. to prepare exams', and 'Usually'. According to the received answers, half of the students never study in-group (50.5\%), while for the students who study in-group, only the $9.0 \%$ do it usually, and the rest of them $(40.5 \%)$ only do it occasionally.

While the computer seems to be already considered a technology undoubtedly connected with the study, mobile devices are newcomers and probably not seen as equally useful tools by the students. With the next question we wanted to know about the use of mobile devices by the students for studying. Additionally, we also wanted to know which mobile devices were preferred by the students, and then the question asked on different types of devices: Do you use the smartphone, the tablet or ebook reader in your study sessions?. The answer considered three alternative options: 'Never', 'Sometimes', and 'Absolutely yes'.The results obtained in this case (see Table III) reflect that the smartphone is the most popular device, followed by the tablet and finally the ebook reader.

The question above was related to the generic use of the mobile devices without considering the intended utilization.
TABLE III. USAGE OF MOBILE DEVICES AT STUDYING SESSIONS (\%)

\begin{tabular}{lccc}
\hline Type of device & No & Sometimes & Decisively yes \\
\hline Smartphone & 51.4 & 36.9 & 11.7 \\
Tablet & 81.1 & 12.6 & 6.3 \\
Ebook & 91.0 & 7.2 & 1.8 \\
\hline
\end{tabular}

TABLE IV. PERCEIVEd Utility OF MOBILE DEVICES (\%).

\begin{tabular}{lccc}
\hline Operation & Very Unhelpful & Quite Useful & Very Useful \\
\hline Search information & 9.0 & 39.6 & 51.4 \\
Access information & 11.7 & 38.7 & 49.6 \\
Share information & 14.4 & 46.0 & 39.6 \\
Organize agenda & 24.3 & 36.1 & 39.6 \\
\hline
\end{tabular}

TABLE V. UtILIZATION OF MOBILE DEVICES WHILE BEING INSTRUCTED (\%).

\begin{tabular}{cccc}
\hline No & No, but I could & Yes, I do & Yes, promoted by the teacher \\
\hline 17.1 & 38.8 & 42.3 & 1.8 \\
\hline
\end{tabular}

As not all the mobile devices have the same capabilities, to know how the students use the smartphones while learning it is important to understand the possibilities and reach of each device. So, the students were asked about four possible uses for each type of mobile device: sharing information, organizing the agenda, accessing to information, and searching for information. The answers for each of the considered devices had to be chosen among three possible answers: 'Very Unhelpful', 'Quite Useful' and 'Very Useful'. The results of this question are shown in Table IV. From the results there, can be concluded that the students use the mobile devices to search, retrieve, share and organize information, in this order of preeminence.

The questions asked up to now dealt with the use done by the students in their work. But an important issue is if these devices are being integrated in the formal classroom teaching or lecturing, as computers have been, or not. Then, in order to know about the use of mobile devices in the classroom, the students were asked whether mobile devices are allowed or not in the classroom and if the educators incentive its use. Four possible answers were considered for the question Do you use any mobile device at classroom? : 'Not, and they are not allowed in the classroom', 'Not, but I could use them in the classroom', Yes, and I use them', and 'Yes, and promoted by the teacher'. The obtained results are shown in Table V.

In order to avoid a rejection intention on the student, it was decided not to ask directly the student about having a smartphone. Instead, an indirect estimation can be made from the results in Table V that at least the $83 \%$ of the students have one, considering the students that use it and those that don't use but could use. From the results above, it can be seen that more than the $44 \%$ of the students use the mobile devices in the classroom, though its use is probably not always connected with learning. But an important result in that table is that only the $1.8 \%$ of the students use mobile devices in the classroom as part of the activities proposed by the teachers.

The question now is to know why those who don't use mobile devices don't do it. The important issue, beyond the permission or not, is if the students perceive that mobile devices are useful in the classroom or not. The results to this question draw the following data. The $53.8 \%$ of the students 
TABLE VI. ACADEMIC RESULTS IN PERCENTAGE OF THE STUDENTS.

\begin{tabular}{ccccc}
$\begin{array}{l}\text { Problems } \\
\text { to pass }\end{array}$ & & & & $\begin{array}{c}\text { Pass at } \\
\text { first try }\end{array}$ \\
\hline 1 & 2 & 3 & 4 & 5 \\
5.4 & 12.6 & 18.0 & 29.7 & 34.3 \\
\hline
\end{tabular}

TABLE VII. SATISFACTION WITH THE ACADEMIC RESULTS (\%) OF ONESELF.

\begin{tabular}{ccccc}
\hline $\begin{array}{c}\text { Strongly } \\
\text { disagree }\end{array}$ & & & & $\begin{array}{l}\text { Strongly } \\
\text { agree }\end{array}$ \\
\hline 1 & 2 & 3 & 4 & 5 \\
9.0 & 25.3 & 36.9 & 20.7 & 8.1 \\
\hline
\end{tabular}

who don't use mobile devices in the classroom think that they are unhelpful in the classroom and that could be the reason why they don't use them. However, the other $46.2 \%$ believes that they are useful, though still they don't use them. This presents a somehow contradictory situation in which a tool perceived as useful for learning isn't used probably due to external considerations or preconceived ideas.

As there is a great concern about the influence of the use of mobile devices on the students' academic results, two items were asked to infer any possible relationship between the use of mobile devices and academic results. Once more, to gather objective data while getting a good acceptance of the survey it is necessary a careful and tactful wording of the question. So, first the students were asked to answer about their academic results choosing among five possible values from 'I have problems to pass some subject along years' to 'I pass all the subject at the first try'. The results of this query are shown in Table VI.

Second, the students were also asked about their satisfaction with the academic results with respect to the effort done in the study. This item was focused in the students' subjective perception of their results regarding the time inverted in the study. The students had to use a 5-point Likert scale to qualify their satisfaction with the results: $1=$ strongly disagree, $3=$ neutral, $5=$ strongly agree. Table VII shows the results of this topic. The reason of asking this question was to know the students' satisfaction with their results and if they see any correspondence between their perception of the work done and the obtained results.

The average of the satisfaction of the students with their academic results is 2.9 with a standard deviation of 1.3. From these data one can see that students don't perceive a strong disagreement between the grades obtained and the effort done.

\section{Discussion}

Once it have been showed the main results, in this section will be discussed and answered the research queries proposed in this work.

First of all, it have to be pointed out that this survey's results can be considered location and time dependent. About this, one can, for example, see the differences in values with some results on teens computer and tablet ownership given in the survey [4] done for an USA population, as well as the evolution of the results with time given there.

Concerning the degree of penetration of mobile devices in study activities, can be concluded, from the results in the
TABLE VIII. GROUP STUDY DEGREE RELATED TO THE USE OF MOBILE DEVICES (\%).

\begin{tabular}{lll}
\hline Frequency of group study & No & Yes \\
\hline Never & 50.0 & 50.0 \\
Sometimes & 35.6 & 64.4 \\
Usually & 30.0 & 70.0 \\
\hline
\end{tabular}

survey, that the $57.7 \%$ of the students use, with different intensity, some of the mobile devices considered in the study, while the $42.3 \%$ never use a mobile device. These data agree with the results reported in [5]. From Table III the preferred mobile device is the smartphone (48.7\%), followed by tablets $(18.9 \%)$ and ebook readers $(9.0 \%)$. The use of ebook readers, as independent devices, is marginal, as can be seen in Table III, and the two works mentioned above also corroborate this conclusion. Regarding the tablet, the current difference in use with the smartphones can be justified because tablets are in an younger stage of implantation while smartphones, which were introduced earlier in the market, are more accessible and their use justified beyond the nowadays main multimedia hub use of the tablets. However, we believe that the difference in percentages of use will be significantly reduced in a next future, according to the observation of the students' adoption of tablets in the last years. Anyway, from the data above can be stated that students are incorporating mobile devices in their academic activities.

At the core of this study lays this question: 'What do students use the mobile devices for?' From Table IV one can see that the preferred use of mobile devices is to search for information, followed by using them to access information, to share information and, finally, for organizing and planning. This use of mobile devices within the academic context doesn't match exactly with what is observed in real life, where the main use of mobile devices is sharing information [6].

This fact introduces us to an interesting clue to understand the nature of the process of implantation of mobile devices in the academic environment. Prior to this, let's try to answer two main issues. First, Can this discrepancy between the usage of mobile devices in learning and in normal life be explained because mobile devices use is promoted by the students and not by the system (teachers or institutions) so that the use of mobile devices capabilities is reduced to those more user centered instead of those group (or system) centered? In order to answer this question it has been studied if there is any difference in the use of mobile devices between those who study in group and those who do it individually. Table VIII presents the ratio of mobile device use depending on the way in which the students usually work. On this table can be found a positive correlation between the study in group and the use of mobile devices: the use of mobile devices increases with increasing time of work in-group. These results allow us to assert that the habit of studying in-group and using mobile devices for studying are closely related.

The second issue checked was: Is there any difference in the way the students use these devices depending on their preference, group or individual, to study? In order to answer this question we have analyzed the outcomes of the survey on the preferred use of mobile devices (Table IV) and the method of study (Table II). To do that, we have considered the students 
TABLE IX. PERCEIVED UTILITY OF MOBILE DEVICES RELATED TO THE WAY THE STUDENTS USE TO STUDY.

\begin{tabular}{lcccc}
\hline Method of study & Organizing & Sharing & Accessing & Searching \\
\hline Group & 80.0 & 90.9 & 92.7 & 94.6 \\
Individual & 71.4 & 80.4 & 83.9 & 87.5 \\
\hline
\end{tabular}

who usually or sometimes study in group vs those who never do that, have been compared their opinion about the utility of mobile devices to accomplish the four activities considered. The results of this cross comparison are shown in Table IX.

As can be seen there, students who work in groups consider that mobile devices are more useful tools for any task than the students who study individually. The difference between the uses by in-group and individual students varies between the $7.1 \%$ for 'searching' and the $10.5 \%$ for 'sharing', what is consistent with the difference in the type of study: working in groups gives an added value to the use of mobile devices, and this is especially noticeable for 'sharing'. Anyway, both, ingroup and individual students use mobile devices for 'searching', 'accessing', 'sharing' and 'organizing' with that order of preeminence.

These results in Table IX represent accurately which of the mobile devices uses are perceived as more or less useful depending on the way the students study. Can be observed that students who study in groups perceive that sharing and organizing are useful/important functions for their study in group, while for the students who study individually searching is a useful/important function in mobile devices when studying. On the other hand, accessing information seems to have a similar importance for both populations. Therefore, there seems to be a correlation between the usual way in which smartphones are employed in everyday life and the way in which they are used by the students who study in group. This permits us to conclude that group study activities are the preferred target for the use of mobile devices. In fact, the daily experience with students shows that smartphones allow the students to form groups while they are in different physical places, given the necessary group interconnection.

From data in Tables V can be observed some relevant aspects of the implication of teachers and institutions in the use of mobile devices by students. First, only the $17.1 \%$ of students have the use of mobile devices forbidden in the classroom. This could induce an optimist perspective of the integration of mobile device in learning activities; however it would be quite erroneous because only the $1.8 \%$ of the students use mobile devices encouraged by the teacher. This allows us to suppose that the rest do it by their own initiative. This lack of collaboration of the teachers can be a cause that reduces the potential of mobile devices in academic activities, and it can even be a reason of the possible disruptive effects in classroom, if the mobile devices are used for activities not connected with the learning. From this point of view, the more the mobile devices could be integrated in the academic activities, the more advantages will be obtained of their capabilities and the lower would their negative effects will be.

\section{Conclusions}

In this work has been highlighted the large interest on mobile learning showed by different institutions and professors both for formal and informal learning. We can conclude that more than half of the participants in the survey use some mobile devices with different intensity degree in their study tasks and that the smartphone is the preferred device.

It have been observed that smartphones, tablets and e-books share a common place with the laptop on the desktop for an increasing number of students. Specifically, smartphones offer some useful functions to coordinate and schedule group study activities. There is a noticeable population that study individually and tend to use mobile devices only as a laptop computer, but an also important collectivity uses them in a more social way while studying. It can be observed when the students who use to study in groups perceive that sharing and organizing are important functionalities of mobile devices, whereas those who work individually does not, preferring instead the mobile utility for searching for information.

Another interesting result is that the number of students who use these devices to be on line while studying is similar to the number of those who listen to music during their study time. This isn't aligned with the generalized opinion hold by those against the use of mobile devices while studying on their negative effects in the academic environment. Then, given the fact that students use mobile devices while studying, finding new ways to integrate those devices use in the studying activities is a challenging task; the objective is to induce in the students the habit of using mobile devices anytime and anywhere to learn or to do activities connected with learning.

\section{ACKNOWLEDGEMENTS}

Thanks are due to every student which participated on the survey and the members of the HESTELO research project, specially to Javier Alonso Nuñez. This work has been funded by the Cátedra Telefónica "Movilidad y Educación" initiative at the University of Valladolid.

\section{REFERENCES}

[1] C. Quinn. (2000) mlearning: Mobile, wireless and in-your-pocket learning. http://www.linezine.com/2.1/features/cqmmwiyp.htm [On line. Last Accessed: 31/10/2012].

[2] J. Vegas, C. Llamas, M. González, and J. Alonso, "Encuesta sobre hábitos de estudio y movilidad," Cátedra Telefónica de la Universidad de Valladolid, Tech. Rep., Nov 2012.

[3] G. Clough, A. Jones, P. McAndrew, and E. Scanlon, "Informal learning with pdas and smartphones," Journal of Computer Assisted Learning, vol. 24, no. 5, pp. 359-371, 2008.

[4] M. Madden, A. Lenhart, M. Duggan, S. Cortesi, and U. Gasser, "Teens and technology 2013," The Pew Research Center's Internet and American Life Project (The Berkman Center for Internet \& Society at Harvard University), Tech. Rep., 2013.

[5] F. Yu and A. Conway, "Mobile/smart phone use in higher education," in Proceedings of the 2012 Southwest Decision Sciences Institute, M. Rao, Ed., 2012, pp. $831-839$.

[6] Nielsen, "The mobile consumer, a global snapshot," The Nielsen company, Tech. Rep., 2013. 